\title{
Pathogen surveillance in wild bottlenose dolphins Tursiops truncatus
}

\author{
Crystal Jaing ${ }^{1, *}$, James B. Thissen ${ }^{1}$, Shea Gardner ${ }^{2}$, Kevin McLoughlin ${ }^{2}$, \\ Tom Slezak ${ }^{2}$, Gregory D. Bossart ${ }^{3}$, Patricia A. Fair ${ }^{4}$ \\ ${ }^{1}$ Physical \& Life Sciences Directorate, ${ }^{2}$ Computations Directorate, Lawrence Livermore National Laboratory, Livermore, \\ CA 94551, USA \\ ${ }^{3}$ Georgia Aquarium, NW Atlanta, GA 30313, USA
}

${ }^{4}$ NOAA/National Ocean Service, Center for Coastal Environmental Health \& Biomolecular Research, Charleston, SC 29412, USA

\begin{abstract}
The number and prevalence of diseases is rapidly increasing in the marine ecosystem. Although there is an increase in the number of marine diseases observed world-wide, current understanding of the pathogens associated with marine mammals is limited. An important need exists to develop and apply platforms for rapid detection and characterization of pathogenic agents to assess, prevent and respond to disease outbreaks. In this study, a broad-spectrum molecular detection technology capable of detecting all sequenced microbial organisms, the Lawrence Livermore Microbial Detection Array, was used to assess the microbial agents that could be associated with wild Atlantic dolphins. Blowhole, gastric, and fecal samples from 8 bottlenose dolphins were collected in Charleston, SC, as part of the dolphin assessment effort. The array detected various microbial agents from the dolphin samples. Clostridium perfringens was most prevalent in the samples surveyed using the microarray. This pathogen was also detected using microbiological culture techniques. Additionally, Campylobacter sp., Staphylococcus sp., Erwinia amylovora, Helicobacter pylori, and Frankia sp. were also detected in more than one dolphin using the microarray, but not in culture. This study provides the first survey of pathogens associated with 3 tissue types in dolphins using a broad-spectrum microbial detection microarray and expands insight on the microbial community profile in dolphins.
\end{abstract}

KEY WORDS: Diagnostics $\cdot$ Microarray $\cdot$ Microbial community $\cdot$ Molecular detection $\cdot$ Marine diseases $\cdot$ Microbiological culture

\section{INTRODUCTION}

The number and prevalence of diseases found in the marine ecosystem is increasing (Harvell et al. 1999, Ward \& Lafferty 2004, Fey et al. 2015). While several factors have been associated with this increase, the cause of this increase is not known and the pathways of disease transmission are either not known or poorly understood. An unprecedented survey of seabirds, marine mammals, and sharks on the US East Coast revealed that marine wildlife contains a wide variety of disease-causing microbes, includ-

${ }^{*}$ Corresponding author: jaing2@llnl.gov ing many that have developed resistance to antibiotics and several that can be transmitted to humans (Bogomolni et al. 2008). Increases have occurred in disease reports for marine mammals (Ward \& Lafferty 2004, Gulland \& Hall 2007). The incidence of these diseases is increased by (1) new combinations of hosts and pathogens creating an environment favoring the emergence of pathogens in novel species, and (2) anthropogenic factors including contaminants and human activity patterns that stress marine hosts and decrease their capacity to develop appropriate immune responses. Newly described or

() The authors 2015. Open Access under Creative Commons by Attribution Licence. Use, distribution and reproduction are unrestricted. Authors and original publication must be credited. 
reemerging disease agents or diseases affecting marine mammals include morbilliviruses (Raga et al. 2008), papillomaviruses, dolphin poxvirus (Bracht et al. 2006), lobomycosis, and various neoplastic diseases (Bossart 2011). An estimated $75 \%$ of emerging infectious diseases are zoonotic (Chomel et al. 2007) with anthropogenic influences being a common factor in the emergence and reemergence of zoonotic pathogens (Daszak et al. 2001).

Emerging known and unknown pathogens create profound threats to wildlife. Recently, a summary of 76 pathogens that were identified in marine mammals was used to develop a risk analysis for cetaceans (Venn-Watson \& Stamper 2011). The 10 highest priority pathogens among small cetaceans were morbillivirus, parapoxvirus, Brucella spp. anisakis, calicivirus, herpesvirus, nasitrema, Clostridium spp., and toxigenic Escherichia coli. Characterization of the bacteria and fungi isolated by culture of samples obtained from dolphins inhabiting the estuarine waters of Charleston, SC and the Indian River Lagoon, FL resulted in observations of a number of pathogenic species (Morris et al. 2011). Antibioticresistant bacteria have also been documented in wild dolphins (Greig et al. 2007, Stewart et al. 2014).

While molecular diagnostics have greatly improved the ability to find microbes in marine mammal samples, it has been difficult to assess the impact of pathogens on both individual and population health of marine mammals. One obstacle to better understanding cetacean pathogens is the difficulty of diagnosing the cause of disease in marine mammals. During mortality events, some pathogens can be detected in tissues although it is unknown whether the pathogen contributed to the cause of death or to an underlying condition. For wild populations, a more thorough understanding of baseline exposures to pathogenic agents would provide further understanding on the diagnostic interpretation of pathogens that may be present during mortality events. However, current dolphin health assessment studies include detection only of those microbial and viral agents for which tests are available. There is an important need for the development of rapid response capability using molecular and microbiological diagnostics to identify and study an array of pathogens to which marine mammals may be exposed. Platforms for rapid detection and characterization of pathogenic agents are critically needed to assess, prevent and respond to disease outbreaks.

Recent advances in genomic-based technologies have revolutionized the study of microbial ecology and its influence on infectious diseases in humans
(Shafquat et al. 2014). PCR and DNA sequencing approaches have been widely used for pathogen detection and characterization. PCR assays are limited in that only a single or few organisms can be investigated per assay. While DNA sequencing can identify a larger scope of organisms, current DNA sequence analysis methods are lengthy, costly and require significant computational time, and there is a lack of bioinformatic tools to rapidly identify and quantify abundances of species identified in a sample. In an effort to improve high-throughput analysis and detection, Gardner et al. (2010) developed an innovative microarray platform called the Lawrence Livermore Microbial Detection Array (LLMDA) to probe for all known microbiological agents for which whole genomes, segments and plasmid sequences are available. Each probe tests for a particular sequence of DNA and small groups of probes can be used to check for specific bacteria or viruses up to the species level. The microarray targets both conserved and unique genomic regions of sequenced microbial strains. Multiple microbe targets provide confirmation and can serve as an internal validation mechanism. Ease of use by diagnostic personnel is provided by an automated data analysis algorithm, Composite Likelihood Maximization Method (CLiMax), which is integrated with a web interface that enables LLMDA data analysis within 30 min.

In this study, both the microbiological culture method and the molecular detection method, the LLMDA were used to analyze the pathogens in blowhole, gastric and fecal samples collected from wild dolphins. The results from the 2 methods were compared and selected pathogens were additionally confirmed using polymerase chain reaction (PCR).

\section{MATERIALS AND METHODS}

\section{Sample collections and assessment}

Dolphin health assessments were performed in Charleston, SC as part of the Bottlenose Dolphin Health and Risk Assessment (HERA) Project. This comprehensive, integrated, multi-disciplinary research study was initiated in 2003, to assess the health status of Atlantic bottlenose dolphins Tursiops truncatus in 2 southeast US sites (Charleston, SC and the Indian River Lagoon, FL) and investigate associations between health status and environmental stressors. Detailed information pertaining to the study site, methods for capture, sampling and release are described by Fair et al. (2006). During the sampling 
process, each animal received an entire physical examination, including full body photo-documentation, diagnostic ultrasound, blood and urine collection, blubber and lesional biopsies, and microbiologic and cytologic sampling of the blowhole, gastric fluid and feces as described (Fair et al. 2006). In August 2013, health assessments were performed on 19 dolphins from the estuarine waters of Charleston, SC under National Marine Fisheries Permit No. 14352-02 and approved by the Florida Atlantic University Institutional Animal Care and Use Committee. Swab samples were collected from blowhole, gastric fluid and anus from 8 dolphins and selected for analysis for pathogen comparisons using LLMDA and microbiological methods (Table 1). The other 11 dolphins did not have all 3 types of swabs collected, and were not included in the present study. Age was determined by counting post-natal dentine layers in an extracted tooth (Hohn et al. 1989). In addition to these pathogen tests, samples were collected to determine clinical and immune status, disease and contaminant exposure and antibiotic resistant organisms.

\section{Lawrence Livermore Microbial Detection Array analysis}

Samples were collected from blowhole, gastric fluid and anus using sterile swabs and placed in cryovials with RNA Later for the microarray analysis. The swab samples were kept cold for $24 \mathrm{~h}$ and then frozen and sent on dry ice to LLNL with the sample types blinded for testing using the LLMDA. This study employed the 12-plex 135000 probe format of this array (version 5), which is restricted to pathogens associated with vertebrate infection, including 1856 viral, 1398 bacterial, 123 archaean, 48 fungal, and 94 protozoan species (current as of December 2011). Strategies for probe design and quality control have

Table 1. Dolphins Tursiops truncatus sampled at Charleston, SC, USA

\begin{tabular}{|lcc|}
\hline Dolphin ID & Gender & Age (yr) \\
\hline 862 & Male & 26 \\
863 & Female & 10.5 \\
866 & Male & 33 \\
886 & Male & 30 \\
$8 \mathrm{~F} 2$ & Male & 22 \\
$8 \mathrm{~F} 4$ & Male & 16 \\
$8 \mathrm{~F} 8$ & Male & 17 \\
8J2 & Male & 33 \\
\hline
\end{tabular}

been previously published (Gardner et al. 2010). Nucleic acids from the swab samples were extracted using a modified protocol of the Qiagen QIAamp cador Pathogen Mini kit. Swabs were placed in $500 \mu \mathrm{l}$ buffer ATL with $20 \mu \mathrm{l}$ Proteinase K for $30 \mathrm{~min}$ at $55^{\circ} \mathrm{C}$. After $30 \mathrm{~min}, 500 \mathrm{mg}$ each of $106 \mu \mathrm{m}$ and $500 \mu \mathrm{m}$ silica/zirconia beads were added to the tubes and the samples were bead-beaten in a Biospec Mini-Beadbeater at speed 48 for $1 \mathrm{~min}$. The samples were centrifuged for $5 \mathrm{~min}$ at $15000 \times g$ and the supernatant was collected. Extraction of the supernatant was completed using the QIAamp cador Pathogen Mini kit following standard manufacturer's protocols. The quantification of RNA and DNA from each sample was determined using the Life Technologies Qubit fluorimeter.

RNA and DNA from each sample were wholegenome amplified using a whole transcriptome amplification kit from Qiagen with modifications as described by Erlandsson et al. (2011). Following the amplification of each sample, one $\mu \mathrm{g}$ of amplified product was fluorescently labeled, purified and hybridized to the 12-plex LLMDA arrays. Data were analyzed using the automated LLMDA 'CLiMax' algorithm (Gardner et al. 2010). The log likelihood for each of the possible targets is estimated from the BLAST similarity scores of the probe and target sequences, together with the probe sequence complexity and other covariates derived from the BLAST results. Presented are the data for sequences that were equal to or greater than the $99 \%$ threshold of random control probes. A minimum of 8 probes per target sequence and greater than $20 \%$ of total probes were used to select for positive detection of target sequences.

\section{Microbiological assessment}

Microbiological assessments of blowhole, gastric and fecal swabs were performed by Micrim Laboratories (Fort Lauderdale, FL) for aerobic and anaerobic microbes as previously described (Morris et al. 2011). Briefly, collection of samples from blowhole, gastric fluid and anus for aerobic, anaerobic and fungal cultures were made using Aimes culturettes (MML Diagnostics). Samples were stored in coolers each day and sent on cold packs overnight for analysis. As part of the comprehensive health screening of the Dolphin HERA Project, clinical approaches were used to characterize the bacteria and fungi isolated from the upper respiratory tract (blowhole), gastric fluid, and anus of wild bottlenose dolphins (Tursiops truncatus). 


\section{PCR analysis of $E$. coli in samples}

A set of samples that had E. coli detected in the microbial assessment, but not on the LLMDA was tested with an E. coli real-time PCR assay. Pan E. coli PCR primers (forward: 5'-GGC GAA GCG GCA AAT TTC ; reverse: 5'-CCG CAG TAA CCA CAG TAT; and probe (5'-FAM-GGG TCG GTA CGT CAG GTC ATT GAT CTC-BHQ) were designed at LLNL as described by Gardner et al. (2009), and manufactured by Integrated DNA Technologies. For each reaction approximately $0.5-1.0 \mathrm{ng}$ of extracted DNA from each tested sample was used. Each $20 \mu \mathrm{l}$ reaction was constructed using the Life Technologies TaqMan ${ }^{\circledR}$ Fast Universal PCR Master Mix (Cat. 4352042) using the manufacturer's recommended protocols. The reactions were cycled for 1 cycle of 2 min at $50^{\circ} \mathrm{C}, 1$ cycle of $10 \mathrm{~min}$ at $95^{\circ} \mathrm{C}$, and 45 cycles of $\left[15 \mathrm{~s}\right.$ at $95^{\circ} \mathrm{C}, 1 \mathrm{~min}$ at $60^{\circ} \mathrm{C}$ ]. All tested samples were run in triplicate on an Applied Biosystems 7500 Fast instrument.

\section{RESULTS}

\section{Microbiological culture results}

Table 2 summarizes the culture results of the 3 sample types from 8 dolphins. Plesiomonas shigelloides was identified in 7/8 individuals, from both blowhole and fecal samples. Aeromonas hydrophila was cultured from 6/8 individuals, in both blowhole and fecal samples. Other bacteria that were culturable from both blowhole and fecal samples are $E d$ wardsiella tarda, Klebsiella pneumoniae and E. coli. Gastric samples did not grow as many bacteria as fecal or blowhole samples. Bacillus sp. was only iden-

Table 2. Summary of microbial organisms identified by microbiological culture. Sample sources are blowhole (B), gastric fluid (G), fecal (F). Data are from 8 dolphins

\begin{tabular}{|lcc|}
\hline Organism & Source & No. positive \\
\hline Aeromonas hydrophila & B, F & 6 \\
Bacillus sp. & G & 1 \\
Candida glabrata & G & 1 \\
Clostridium perfringens & F & 1 \\
Escherichia coli & B, F & 3 \\
Edwardsiella tarda & B, F & 5 \\
Enterobacter cloacae & B & 2 \\
Klebsiella pneumoniae & B, F & 2 \\
Plesiomonas shigelloides & B, F & 7 \\
Pseudomonas fluorescens & B & 2 \\
\hline
\end{tabular}

tified from Dolphin 863, and a yeast Candida galbrata was cultured from Dolphin 886. Of the microbes cultured from the samples, only Clostridium perfringens in the fecal sample of Dolphin 863 was detected by both microarray and culture.

\section{Microarray analysis of dolphin samples}

Nucleic acids extracted from gastric, fecal and blowhole swab samples were analyzed on the LLMDA array. The pathogens detected by the array are shown in Table 3.

Clostridium was detected in 4/8 dolphins and in all 3 sample types, blowhole, fecal and gastric. All other organisms were not detected by culture. This data suggested that the organisms detected by molecular techniques could be either unculturable, or slow growing and not identifiable by standard culture techniques.

An example of the microarray data from Dolphin 886 (fecal sample) is shown in Fig. 1, including logodds ratios and the array probes detected vs. expected for the 4 bacterial and 1 viral families. Targets are grouped by taxonomic family and are listed within families in decreasing order of conditional logodds scores.

Table 3. Summary of microbial signatures detected by the Lawrence Livermore Microbial Detection Array. Sample sources are blowhole (B), gastric fluid (G), fecal (F). Data are from 8 dolphins

\begin{tabular}{|lcc|}
\hline Organism & $\begin{array}{c}\text { Sample } \\
\text { source }\end{array}$ & $\begin{array}{c}\text { No. } \\
\text { positive }\end{array}$ \\
\hline Brevibacillus brevis & G & 1 \\
Campylobacter lari 300 & B, G, F & 2 \\
plasmid pCL300 & B, G, F & 4 \\
Clostridium perfringens & F & 1 \\
Clostridium phage phiSM101 & B & 1 \\
Cyanothece sp. CCY0110 & B, G & 2 \\
Erwinia amylovora IL-5 plasmid & B & 1 \\
Exiguobacterium sp. AT1 & B, G & 3 \\
Frankia sp. EUN1f & F & 2 \\
Helicobacter pylori plasmid & G & 1 \\
Lyngbya majuscula 3L & F & 1 \\
Photobacterium damselae & G & 1 \\
Planococcus donghaensis MPA1U2 & G & 1 \\
Propionibacterium phage PA6 & G & 2 \\
Staphylococcus sp. plasmid & F & 1 \\
Tursiops truncatus & & \\
papillomavirus type 1 & F & 1 \\
Vibrio phage Vf12 & & \\
\hline
\end{tabular}




\section{Probe Counts}

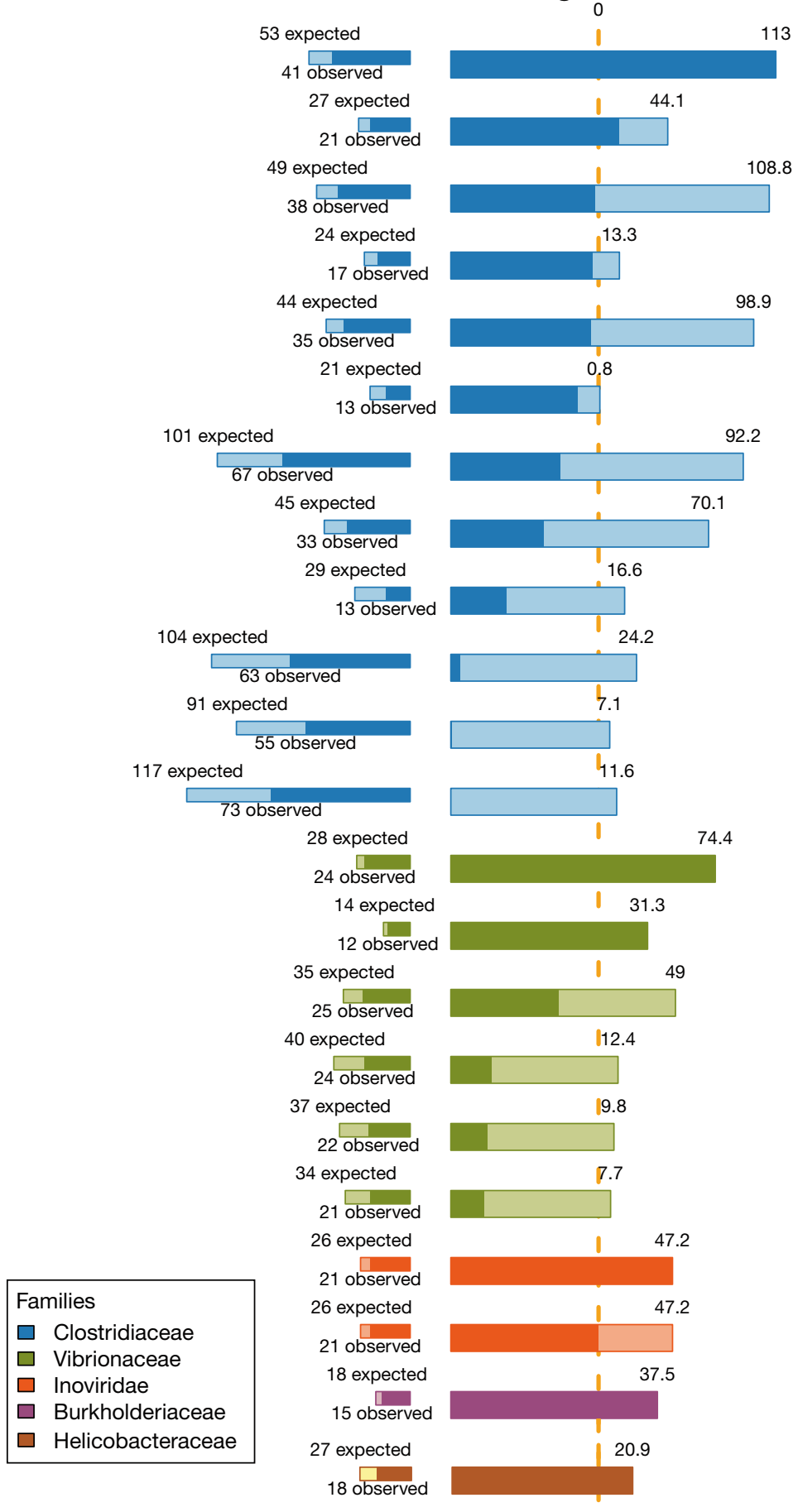

Clostridium perfringens SM101 chromosome, complete genome

Clostridium perfringens F5603 plasmid pBCNF5603, complete sequence

Clostridium perfringens NCTC 8239

Clostridium perfringens SM101 plasmid pSM101B

Clostridium perfringens str. 13, complete genome

Clostridium perfringens SM101 plasmid pSM101A

Clostridium perfringens D str JGS1721

Clostridium perfringens ATCC 13124 chromosome, complete genome

Clostridium beijerinckii NCIMB 8052 chromosome, complete genome

Clostridium perfringens E str JGS1987

Clostridium perfringens CPE str F4969

Clostridium perfringens C str JGS1495

Photobacterium damselae subsp. piscicida plasmid pPHDP10, complete sequence

Photobacterium damselae chr1

Photobacterium damselae plasmid1

Photobacterium damselae subsp. damselae plasmid pPHDD1, complete sequence

Photobacterium damselae plasmid2

Photobacterium damselae plasmid3

Vibrio phage Vf33

Vibrio phage Vf12

Ralstonia pickettii 12D plasmid pRp12D02, complete sequence

Helicobacter pylori PeCan4 plasmid pHPPC4

Fig. 1. Microarray results of Dolphin 886 fecal sample, analyzed using the CLiMax analysis. Red text: Targets predicted as likely to be present. Log CL ratio bar graphs: log-odds scores for corresponding predicted target genome; darker and lighter portions represent the conditional and unconditional scores, respectively (conditional score shows the contribution from a target that cannot be explained by another, more likely target above it; unconditional score illustrates that some very similar targets share a number of probes, so that multiple targets may be consistent with the hybridization signals). Probe count bar graphs provide some additional guidance for interpreting the prediction results: larger 'expected' score is obtained by summing the conditional detection probabilities for all probes; smaller 'observed' score (darker portion) is derived by limiting this sum to probes that were actually detected. Because probes often cross-hybridize to multiple related genome sequences, numbers of expected and detected probes often greatly exceed the number of probes actually designed for a given target organism 
Clostridium perfringens, Photobacterium damselae, Vibrio phage Vf12 and Helicobacter pylori plasmid were detected by microarray in this individual. The microarray data from the other dolphins are provided in the Supplement (www.int-res.com/articles/ suppl/d116p083_supp.pdf); no microorganisms were detected from Dolphin 8F2 using the microarray.

\section{PCR analysis of $E$. coli}

To further confirm the different results from culture and microarray, we performed PCR testing of E. coli on selected dolphin samples. E. coli was found in 3 samples (from Dolphins 863, 866 and 886) by culture, but not detected by array. PCR results are summarized in Table 4. A gastric sample from Dolphin 8F8 which was negative by culture was also included as a negative control. All samples were negative by PCR, suggesting that the results agree with the microarray results, but not with culture.

\section{DISCUSSION}

Effective surveillance of both wild and managedcare bottlenose dolphins is important to assess the general health of marine mammals and the environmental conditions in the surrounding coastal ecosystem. Classification of the health status of bottlenose dolphins revealed a high prevalence of diseased dolphins, with less than $50 \%$ of bottlenose dolphins inhabiting the estuarine waters of Charleston classified as healthy (Reif et al. 2008). Analysis of the microbiome of marine mammals could provide information on the potential association of pathogens with diseases (Nelson et al. 2015).

In this study, we assessed the microbial profiles associated with blowhole, gastric, and fecal samples from 8 wild dolphins using both culture and cultureindependent methodologies. By coupling pathogen measurements using traditional microbiological tests with the broad-spectrum pathogen detection technology, LLMDA, we were able not only to test for those organisms previously known to infect marine mammals, but also to survey for additional pathogens that could be associated with these animals. The molecular analysis revealed a bacterial community very different from that detected in culturebased studies. This community included plant, marine, and dolphin infecting microbes that one may not expect to be detectable by common culturing methods.
Table 4. E. coli real-time PCR data to verify the negative detection of $E$. coli by microarray. Sample sources are blowhole (B), gastric fluid (G), fecal (F). nd: E. coli not detected; na: not applicable

\begin{tabular}{|lcccc|}
\hline Sample & Type & $\begin{array}{c}\text { Concentration } \\
\left.\text { (ng reaction }{ }^{-1}\right)\end{array}$ & $\begin{array}{c}\text { PCR Ct } \\
\text { Mean }\end{array}$ & SD \\
\hline Dolphin 863 & F & 1.0 & nd & na \\
Dolphin 866 & F & 0.5 & nd & na \\
Dolphin 886 & B & 1.0 & nd & na \\
Dolphin 886 & F & 1.0 & nd & na \\
Dolphin 8F8 & G & 0.6 & nd & na \\
E. coli strain & $\begin{array}{c}\text { Positive } \\
\text { ATCC 43895 }\end{array}$ & 1.0 & 24.03 & 0.08 \\
Control & Negative & na & nd & na \\
& control & & & \\
\hline
\end{tabular}

The bacterium that was detected by both microarray and culturing methods, Clostridium perfringens, causes death and disease in dolphins (Buck et al. 1987). C. perfringens is a Gram-positive bacterium that exists in spore form in the environment and can cause serious infection in dolphins via skin wounds. The other microorganisms detected by the microarray included a wide diversity of bacteria, viruses, and phages. Brevibacillus brevis, Erwinia amylovora, and Frankia sp. are plant- or fungal-infecting pathogens that have not been implicated in dolphin health. In addition, there were a number of marine-related bacteria that do not appear to be linked to dolphin disease. These include the nitrogen-fixing Cyanothece sp., Exiguobacterium sp., Planococcus donghaenisis, and the blue alga Lyngbya majuscule.

In addition to $C$. perfringens, the microarray identified several bacterial and viral species that have been associated with dolphin and/or mammalian disease. Campylobacter lari is found in the gastrointestinal tracts of mammals and birds and causes several gastrointestinal associated diseases in humans (Broczyk et al. 1987, Otaševic et al. 2004). Campylobacter species have been found in marine mammals, e.g. Campylobacter insulaenigrae, a near neighbor of C. lari, in rectal swabs of 2 different marine mammals: common seals Phoca vitulina and harbor porpoise Phocoena phocena (Foster et al. 2004). Photobacterium damselae was also identified by the microarray. This bacterium has been found in ocean water, seaweed, and has been isolated as a pathogen in dolphins (Rivas et al. 2013). P. damselae, also known as Vibrio damselae, has been associated with wound infections in humans: $P$. damselae caused fulminant septicemia in a man after filleting bluefish (Perez-Tirse et al. 1993); and fatal renal failure 
occurred due to $P$. damselae infection of the hand of a fisherman (Yamane et al. 2004). Thus, this marine pathogen could potentially impact human health. Lastly, the microarray identified the virus Tursiops truncatus papillomavirus in one of the sampled animals. This papillomavirus has been associated with oral and genital papillomas in dolphins, and identified in free-ranging dolphin populations (Rehtanz et al. 2012). Papillomavirus is a common infection in dolphins (Bossart 2011) and first reported in wild dolphins inhabiting the estuarine waters of Charleston, SC and the Indian River Lagoon, FL (Rehtanz et al. 2006). The detection of Tursiops truncatus papillomavirus type 1 from a fecal sample of Dolphin 8F8 was even more interesting because a biopsy sample collected from this dolphin was confirmed for genital papilloma (G. D. Bossart, data not shown).

Clostridium perfingens was the only bacterium detected by both culture and molecular analyses. Culture-based approaches tend to overestimate bacteria that grow easily, and underestimate those that are slow-growing or that need a specific growth medium (Fuhrman et al. 1993, Amann et al. 1995, Davies et al. 2004). Johnson et al. (2009) investigated upper respiratory samples from dolphins $(\mathrm{n}=4)$ using bacterial 16S rDNA, and detected almost no overlap with the taxa found via culture-based methods, except for Bacteroides fragilis. Comparative analysis of microarray vs culture in human wound samples also showed discrepancy between the 2 techniques (Be et al. 2014); LLMDA detected at least one pathogen in $34 \%$ of the samples that were culture-negative, demonstrating that it was more sensitive in detecting pathogens from wound samples.

While microarray analysis detected some microbial organisms that were negative by culture, the microarray did not detect some organisms that were culture-positive. One explanation of the detection discrepancy is that the sensitivity of the microarray towards different species varies depending on the availability of the genomic data. The array has higher probe coverage for the microbial species that have more genomic sequence data available; therefore the sensitivity for detection of these species will be higher, while the microbial species with fewer known genomic sequences will have fewer probes and lower sensitivity of detection by array (Gardner et al. 2010, Be et al. 2014). Another possibility that could contribute to the detection differences between culture and molecular analyses is that different aliquots of swabs from a given bottlenose dolphin sample were used by the 2 methods. If a pathogen was not homogenously distributed in the samples, the analy- ses would yield different results. Using the 16S rRNA gene sequencing approach, Johnson et al. (2009) assessed microbial diversity of 4 bottlenose dolphins: an average of $20016 \mathrm{~S}$ rRNA sequences was obtained per dolphin, many of which belonged to 3 dominant bacterial phyla: Proteobacteria, Bacteroidetes and Firmicutes. In another study with 24 dolphins also using the 16S rRNA sequencing method, 19 bacterial phyla were observed in exhaled breath samples from the blowhole (Lima et al. 2012).

The present study revealed lower numbers of taxa as compared to previous studies (Johnson et al. 2009, Lima et al. 2012). In this study, the LLMDA version used included probes to detect sequenced vertebrateinfecting pathogens, with limited ability to detect novel or unknown organisms. Additionally, LLMDA was designed to detect unique genomic regions of sequenced microbes, instead of the conserved $16 \mathrm{~S}$ rRNA sequence only. LLMDA achieves better specificity than 16S-based technologies, but detection sensitivity is lower due to the broader coverage of genomic targets. When compared with standard PCR methods on pig clinical samples, the LLMDA was estimated to be about 2 orders of magnitude less sensitive (Jaing et al. 2015). The level of sensitivity was consistent regardless of sample source. Therefore, the array is likely to deliver a positive result of pathogens when relatively large quantities of microbe nucleic acid are present. Larger sample size and a more complete microbiome study will be necessary to further validate data obtained from this study and reveal the microbiome associated with wild bottlenose dolphins. These observations also demonstrated that a combination of clinical, microbiological and molecular approaches will provide more comprehensive information on the diversity of the dolphin microbiota.

This study provides the first survey of pathogens associated with 3 tissue types (blowhole, gastric, fecal) from these bottlenose dolphins using a broadspectrum microbial detection microarray technology. LLMDA provides a good platform for rapid and comprehensive detection of all known viruses, bacteria and fungi present in the array. Most existing detection technologies are based on antibody tests or nucleic acid amplification of sequences from one or a small set of organisms. While they are able to rapidly identify selected pathogens at the species or strain level, they cannot be multiplexed to the degree required to broadly detect different organisms. However, it should be noted that microarray results do not imply health status or presence of disease. The microarray provides a surveillance of the various microorganisms, and may provide insight on the 
potential association of these organisms with certain diseases and hence, those microorganisms can then be targeted for the development of testing methods. This new technology will allow us to broaden the diagnostic disease base, validate previous findings and provide a comprehensive profile of the microbial community present in a sample. This can then lead to better management of land-based sources of microbial pollution for wild dolphins and potential sources for managed-care dolphins. Future studies will potentially expand our insight into pathogens in dolphins in relation to their overall health as well as ecological health.

Acknowledgements. We thank the numerous researchers who participated in the dolphin capture and release studies in South Carolina. We are especially grateful to B. Joseph, L. Hansen, S. McCulloch, L. Fulford, the NOAA and HBOI staff, the collaborators and veterinarians who provided their expertise, and the many volunteers whose help made the health assessment studies possible. We also thank R. Ober and J. Thompson from Kansas State University for assistance with DNA extraction of some of the dolphin samples during their summer internship at LLNL. This present study was partially supported through Office of Naval Research Award Number N0001411IP20081 and N00014110541.

Disclaimer. This publication does not constitute an endorsement of any commercial product or intend to be an opinion beyond scientific or other results obtained by the National Oceanic and Atmospheric Administration (NOAA). No reference shall be made to NOAA, or this publication furnished by NOAA, to any advertising or sales promotion which would indicate or imply that NOAA recommends or endorses any proprietary product mentioned herein, or which has as its purpose an interest to cause the advertised product to be used or purchased because of this publication.

\section{LITERATURE CITED}

Amann RI, Ludwig W, Schleifer KH (1995) Phylogenetic identification and in situ detection of individual microbial cells without cultivation. Microbiol Rev 59:143-169

> Be NA, Allen JE, Brown TS, Gardner SN and others (2014) Molecular profiling of combat wound infection through microbial detection microarray and next-generation sequencing. J Clin Microbiol 52:2583-2594

Bogomolni AL, Gast RJ, Ellis JC, Dennet M, Pugliares KR, Lentell BJ, Moore MJ (2008) Victims or vectors: a survey of marine vertebrate zoonoses from coastal waters of the Northwest Atlantic. Dis Aquat Org 81:13-38

> Bossart GD (2011) Marine mammals as sentinel species of ocean and human health. Vet Pathol 48:676-690

> Bracht AJ, Brudek RL, Ewing RY, Manire CA and others (2006) Genetic identification of novel poxviruses of cetaceans and pinnipeds. Arch Virol 151:423-438

$>$ Broczyk A, Thompson S, Smith D, Lior H (1987) Water-borne outbreak of Campylobacter laridis-associated gastroenteritis. Lancet 329:164-165

Buck JD, Shepard LL, Spotte S (1987) Clostridium perfringens as the cause of death of a captive Atlantic bottle- nosed dolphin (Tursiops truncatus). J Wildl Dis 23:488-491 Chomel BB, Belotto A, Meslin FX (2007) Wildlife, exotic pets, and emerging zoonoses. Emerg Infect Dis 13:6-11

> Daszak P, Cunningham AA, Hyatt AD (2001) Anthropogenic environmental change and the emergence of infectious diseases in wildlife. Acta Trop 78:103-116

> Davies CE, Hill KE, Wilson MJ, Stephens P, Hill CM, Harding KG, Thomas DW (2004) Use of 16S ribosomal DNA PCR and denaturing gradient gel electrophoresis for analysis of the microfloras of healing and nonhealing chronic venous leg ulcers. J Clin Microbiol 42: 3549-3557

Erlandsson L, Rosenstierne MW, McLoughlin K, Jaing C, Fomsgaard A (2011) The microbial detection array combined with random Phi29-amplification used as a diagnostic tool for virus detection in clinical samples. PLoS ONE 6:e22631

Fair PA, Adams JD, Zolman E, McCulloch SD and others (2006) Protocols for conducting dolphin capture-release health assessment studies. NOAA Tech Memo NOS NCCOS

> Fey SB, Siepielski AM, Nusslé S, Cervantes-Yoshida K and others (2015) Recent shifts in the occurrence, cause, and magnitude of animal mass mortality events. Proc Natl Acad Sci USA 112:1083-1088

Foster G, Holmes B, Steigerwalt AG, Lawson PA and others (2004) Campylobacter insulaenigrae sp. nov., isolated from marine mammals. Int J Syst Evol Microbiol 54: 2369-2373

> Fuhrman JA, McCallum K, Davis AA (1993) Phylogenetic diversity of subsurface marine microbial communities from the Atlantic and Pacific Oceans. Appl Environ Microbiol 59:1294-1302

Gardner SN, Hiddessen AL, Williams PL, Hara C, Wagner MC, Colston BW Jr (2009) Multiplex primer prediction software for divergent targets. Nucleic Acids Res 37 : 6291-6304

> Gardner SN, Jaing CJ, McLoughlin KS, Slezak TR (2010) A microbial detection array (MDA) for viral and bacterial detection. BMC Genomics 11:668

> Greig TW, Bemiss JA, Lyon BA, Bossart GD, Fair PA (2007) Prevalence and diversity of antibiotic resistant Escherichia coli in bottlenose dolphins (Tursiops truncatus) from the Indian River Lagoon, Florida and Charleston Harbor area, South Carolina. Aquat Mamm 33:185-194

Gulland FD, Hall A (2007) Is marine mammal health deteriorating? Trends in the global reporting of marine mammal disease. EcoHealth 4:135-150

Harvell CD, Kim K, Burkholder JM, Colwell RR and others (1999) Emerging marine diseases - climate links and anthropogenic factors. Science 285:1505-1510

Hohn AA, Scott MD, Wells RS, Sweeney JC, Irvine AB (1989) Growth layers in teeth from known-age, freeranging bottlenose dolphins. Mar Mamm Sci 5:315-342

> Jaing CJ, Thissen JB, Gardner SN, McLoughlin KS and others (2015) Application of a pathogen microarray for the analysis of viruses and bacteria in clinical diagnostic samples from pigs. J Vet Diagn Invest 27:313-325

Johnson WR, Torralba M, Fair PA, Bossart GD, Nelson KE, Morris PJ (2009) Novel diversity of bacterial communities associated with bottlenose dolphin upper respiratory tracts. Environ Microbiol Rep 1:555-562

> Lima N, Rogers T, Acevedo-Whitehouse K, Brown MV (2012) Temporal stability and species specificity in bacteria associated with the bottlenose dolphins respiratory 
system. Environ Microbiol Rep 4:89-96

Morris PJ, Johnson WR, Pisani J, Bossart GD, Adams J, Reif JR, Fair PA (2011) Isolation of culturable microorganisms from free-ranging bottlenose dolphins (Tursiops truncatus) from the southeastern United States. Vet Microbiol 148:440-447

Nelson TM, Apprill A, Mann J, Rogers TL, Brown MV (2015) The marine mammal microbiome: current knowledge and future directions. Microbiol Aust 36:8-13

Otaševic MM, Lazarevic-Jovanovic B, Tasic-Dimov D, Dordevic N, Miljkovic-Selimovic BG (2004) Participation of some Campylobacter species in the etiology of enterocolitis. Vojnosanit Pregl 61:21-27

Perez-Tirse J, Levine JF, Mecca M (1993) Vibrio damsela. A cause of fulminant septicemia. Arch Intern Med 153: 1838-1840

Raga JA, Banyard A, Domingo M, Corteyn M and others (2008) Dolphin morbillivirus epizootic resurgence, Mediterranean Sea. Emerg Infect Dis 14:471-473

Rehtanz M, Ghim SJ, Rector A, Van Ranst M, Fair PA, Bossart GD, Jenson AB (2006) Isolation and characterization of the first American bottlenose dolphin papillomavirus: Tursiops truncatus papillomavirus type 2. J Gen Virol 87:3559-3565

Rehtanz M, Bossart GD, Fair PA, Reif JS, Ghim Sj, Jenson $A B$ (2012) Papillomaviruses and herpesviruses: Who is who in genital tumor development of free-ranging Atlantic bottlenose dolphins (Tursiops truncatus)? Vet Microbiol 160:297-304

Editorial responsibility: Michael Moore, Woods Hole, Massachusetts, USA
Reif JS, Fair PA, Adams J, Joseph B and others (2008) Evaluation and comparison of the health status of Atlantic bottlenose dolphins from the Indian River Lagoon, Florida, and Charleston, South Carolina. J Am Vet Med Assoc 233:299-307

Rivas AJ, Lemos ML, Osorio CR (2013) Photobacterium damselae subsp. damselae, a bacterium pathogenic for marine animals and humans. Front Microbiol 4:283

Shafquat A, Joice R, Simmons SL, Huttenhower C (2014) Functional and phylogenetic assembly of microbial communities in the human microbiome. Trends Microbiol 22: 261-266

Stewart JR, Townsend FI, Lane SM, Dyar E and others (2014) Survey of antibiotic resistance bacteria isolated from bottlenose dolphins Tursiops truncatus in the southeastern USA. Dis Aquat Org 108:91-102

Venn-Watson S, Stamper A (2011) Pilot pathogen prioritization survey results for cetaceans. In: Rowles $\mathrm{T}$ (ed) Working Group on Marine Mammal Unusual Mortality Events. Report SC/62/E4 to the Scientific Committee of the International Whaling Commission. http://iwoffice .org/_documents/sci_com/SC62docs/SC-62-E4.pdf

> Ward JR, Lafferty KD (2004) The elusive baseline of marine disease: Are diseases in ocean ecosystems increasing? PLoS Biol 2:e120

Yamane K, Asato J, Kawade N, Takahashi H, Kimura B, Arakawa Y (2004) Two cases of fatal necrotizing fasciitis caused by Photobacterium damsela in Japan. J Clin Microbiol 42:1370-1372

Submitted: April 21, 2015; Accepted: August 18, 2015 Proofs received from author(s): September 29, 2015 